\title{
Wen Ling \\ Synergetic Management Theory for Coal-Based Energy Engineering and the Engineering Practice of Shenhua
}

\begin{abstract}
To deal with problems in synergetic development of coal-based energy engineering, this paper, guided by the philosophy of engineering, proposes the synergetic management philosophy of "factors coordination, systems synergy, dynamic optimization and three-dimension planning." The paper also establishes the synergetic management system characterized by systems factor synergy, resource-environment synergy and systems boundary extension and supported by the "two-wheel driven" management innovation and technological innovation. In addition, the paper presents a multi-objective dynamic optimization model for energy engineering, designed based on Shenhua's own engineering practice, to analyze Pareto optimal solution in three scenarios: best resource allocation, minimal environmental impact and maximal value creation. This provides important reference to synergetic development strategies and decision-making in engineering management.
\end{abstract}

Keywords: coal-based energy, engineering synergetic management, two-wheel driven innovation, Shenhua engineering

\section{Introduction}

As a fundamental energy resource, coal plays an essential role in securing energy supply, promoting economic development and bolstering employment and social stability in China. It accounts for $96 \%$ of China's fossil fuel reserve, taking up over $75 \%$ of total primary energy production and approximately $65 \%$ of energy consumption in China since 2003 (Xie, 2014). During the "Eleventh Five-Year" period, the coal sector and main coal-consuming industries combined contributed $15 \%$ of China's GDP and $18 \%$ of GDP growth (The National Bureau of Statistics

Manuscript received July 9, 2015; accepted October 25, 2015

Wen Ling $(\bowtie)$

Shenhua Group Corporation Limited, Beijing 100011, China

Email: lingw@shenhua.cc of the People's Republic of China, 2013). By the end of 2013 , the number of people employed in coal mining and the electric and thermal power industry has reached 6.11 million and 3.7 million respectively, accounting for $7.0 \%$ of the total industrial employment in China.

Coal-based energy engineering is giant system engineering that consists of industrial factors such as coal, electric power, coal conversion and transportation as well as associated factors such as resource, environment, management and technologies. Shenhua Group Corporation Limited (hereinafter referred to as "Shenhua") is an energy conglomerate with a unique business model integrating coal, power, railway, port, shipping, coal-to-liquids/chemicals, operating a complete supply chain of production, transportation and trade (Shenhua Group Corporation Limited, 2014). While contributing to the national energy security, the company also pioneered with the multiindustry integrated model, which was included in the "Guidance for Sound Development of Coal Industry" by the state council to be promoted nationwide. In 2014, the company sold $588 \times 10^{6}$ tons of coal, accounting for $15.2 \%$ of total production in China. This generated $324.6 \times 10^{9}$ $\mathrm{kWh}$ of electricity, $7.7 \%$ of the national total; $412 \times 10^{6}$ tons of coal was delivered through its own railway network, $18.0 \%$ of total railway coal delivery in China. Revenue in 2014 stood at $\mathrm{CNY} 328.6 \times 10^{9}$ with total profit of $\mathrm{CNY}$ $64 \times 10^{9}$.

With the rapid development of China's economy and Shenhua's quick extension, challenges arise in areas such as optimization of resources allocation, improvement of quality and efficiency in operation, green development of the coal industry and technological innovation. These challenges have thus become hindrance to sound development of Shenhua and the coal industry at large.

To effectively solve the problems mentioned above, this paper, guided by the philosophy of engineering, while adhering to the principle of coordinated development of resource, environment and economy, proposes synergetic management philosophy for coal-based energy engineering. This is characterized by systems factor synergy, resource-environment synergy and systems boundary 
extension and supported by the "two-wheel driven" management innovation and technological innovation. The paper also designed the multi-objective dynamic optimization model for energy engineering, reviewing Shenhua's own engineering practice from the perspectives of industrial synergy, environmental protection and value creation.

\section{Philosophy of synergetic management of coal-based energy engineering}

\subsection{Major problems in synergetic development of coal-based energy engineering}

Systematic analysis reveals that the main problems of coalbased energy engineering can be found in four areas.

First, there is a lack of coordination in resource allocation. In the case of Shenhua, its coal segment contributed $57.4 \%$ of total profit in 2005 , and $57.5 \%$ in 2008. The fact that coal disproportionately outweighed other businesses of the company resulted in low efficiency in resource allocation, poor synergy and underperformance of the coal-based energy engineering in general.

Secondly, there is lack of green development in coal industry. Green development of Shenhua and the industry is faced with two major challenges: one is land restoration from mining damages; the other is air pollution from the use of coal. There is pressing need for transformation of coal and other relevant industries.

Thirdly, there is an unbalance between quality and benefits of development. Traditional coal industry is only at the upstream of the value chain, which normally neglects the importance of coal-associated resource development and lacks engineering technologies. For instance, China is in short of bauxite and $50 \%$ domestic demand is met by import. On the other hand, around $4 \times 10^{9}$ tons of associated aluminum resource has been discovered in Zhungeer coalfield, 7 times of proven bauxite reserve in China. Ash from burning Zhungeer coal, which contains rich aluminum, was only land-filled or used as simple raw material for construction, causing not only waste but also pollution to the environment.

Fourthly, technological innovation capability is undeveloped. Insufficient investment and weak R\&D foundation are common problems hindering the development of coal industry. In 2013, R\&D expenditure in coal and power industries combined was CNY $35.1 \times 10^{9}$, with an R\&D intensity of merely $0.38 \%$, only $1 / 2$ of the average of the industrial sector and $1 / 5$ of high-tech manufacturing (The National Bureau of Statistics of the People's Republic of China, 2014). Take Shenhua as an example, the company had no directly affiliated R\&D institutions until 2009, and the situation was worsened by severe shortage of talents, incomplete research and innovation mechanisms and poor innovation capabilities. All of these had hampered scientific development of the company.

\subsection{Synergetic management theory for coal-based energy engineering}

A systematic solution to the aforesaid problems through better coordination among various factors is important to sound development of coal-based energy companies and the coal industry as a whole. These factors interrelate with and rely on each other while at the same time constraining and conflicting with each other. The philosophy of engineering is thus required to analyze, coordinate and integrate various factors for better coordination, so as to closely follow the objective rules and achieve harmony between ecology and the society (Yin \& Wang, 2007). In any study of systems sciences, the law of contradiction always serves as the logical starting point (Liu, 1992). The coal-based energy engineering therefore needs to further analyze the contradictory relations between system factors. Systematic thinking, contradiction analysis and coordination are the methodologies to achieve engineering synergy.

Based on Shenhua's own engineering practice, this paper, guided by the philosophy of engineering, proposes the synergetic management philosophy of "factors coordination, systems synergy, dynamic optimization and threedimension planning." It establishes the synergetic management system characterized by systems factor synergy, resource and environment synergy and systems boundary extension and supported by the "two-wheel driven" management innovation and technological innovation.

\subsection{Synergetic management system for coal-based energy engineering}

\subsubsection{Analysis of coal-based energy engineering system}

Coal-based energy engineering is composed of three systems: resource-environment system, boundary extension system and the factors system, which respectively reflect environmental adaptability, evolutionary expansibility and inter-correlation. The environmental adaptability of resource-environment system is demonstrated by the interaction and mutual constraint between coal-based energy engineering and external environment, such as the relation between coal development and ground ecology and the atmosphere. The evolutionary expansibility is demonstrated by the extension of coverage in coal-based energy engineering with the improvement of system capacity, such as the contribution of associated resources to the extension of traditional industry frontier. The correlation of internal factors system is demonstrated by the relations between internal factors of coal-based energy engineering, such as the interactions and relations among coal, power, chemical, railway, ports and shipping. 
2.3.2 Construction and key messages of the synergetic management system for coal-based energy engineering

Sustainable development of coal-based energy engineering is a spiraling up process based on the coordination of quality, quantity and degree, which are three important factors of dialectical materialism. Quality is the internal definitive characteristic that demonstrates the property of a subject while differentiating it from other things. Coalbased energy engineering in the new era should take green development as its qualitative property and pay attention to the balance between resource and environment. Quantity reflects the permutation and combination of the scale, speed and extent of a subject's development in time and space. The multi-industry development of Shenhua should highlight the optimization of quantity and push forward coordination among systems factors. Degree is the quantitative boundary and scope of a subject in maintaining its own property. Shenhua's engineering practice should pay attention to value creation across its industrial chain and promote boundary extension synergy. The synergetic management system consists of systems factor synergy, resource-environment synergy and system boundary extension, which are also interactive and mutually constraining. Resource-environment synergy is the constraint of systems factor synergy and boundary extension. Such synergy is the extension of systems factor synergy and resource-environment synergy, and systems factor synergy is the foundation of resource-environment synergy and boundary extension synergy.

\subsubsection{Resource-environment synergy}

Resource-environment synergy is demonstrated in coal production and utilization, i.e., ecological preservation in production and environmental protection in utilization.

First, Shenhua came up with the coordination model for coal production and ecological protection. With equal importance attached to both mining and ecology, efforts were made to study the relations between mining face parameters and land ecology, establishing an integrated model characterized by the concept of "planning before mining, active damage reduction during mining and blockby-block restoration after mining." In addition, an engineering technical system to coordinate coal mining and land restoration has also been set up. This includes the modern mining technology based on active damage reduction on land ecology, ecological restoration, microorganic boosting technology and water resource optimization and allocation technologies. Findings of the research have been successfully applied in Shendong, the only 200million-capacity modern coal in the world, with green coverage of the mine increasing from $3 \%-11 \%$ before mining to $78 \%$ in 2014 , and coordination efficiency improving from $72 \%$ in 2005 to $91 \%$ in 2014 . Among all
60 Shenhua coal mines, 22 are with $10 \times 10^{6}$ tons annual capacity and 21 have been classified as national "Green Mines." In addition, the coordinative model has also led to establishment of a number of pilot mines, thus contributing to green development of coal resources in China.

Secondly, Shenhua is the first company to propose and implement ultra-low emission coal-fired power generation. With heavy emissions from coal-fired power plants, saturation of environment capacity in east China and public view on pollution from coal use, Shenhua proposed the concept that "coal-fired generation can be as clean as gas-fired generation," identifying ultra-low emission technical pathways for its coal fleet and carrying out ultra-low emission projects with China's first ultra-low emission coal unit coming on line. By the end of June, 2015, Shenhua has 25 ultra-low emission units with combined capacity of $15.66 \mathrm{GW}$, accounting for $41 \%$ of the national total. With generation cost only increasing by about $0.02 \mathrm{CNY}$ per $\mathrm{kWh}$, this technology and the demonstration projects have boosted the development of ultra-low emission coal generation across China.

\subsubsection{Boundary extension synergy}

To address the underdevelopment of coal-associated resources, Shenhua proposed the engineering concept of "efficient and coordinated development and utilization of coal and associated resources." Striving for coordinated development and recycling of associated resources when it is technically and economically viable. This concept breaks away from traditional development method, providing important reference to extension of industrial value chain of coal-based energy engineering. The associated aluminum and gallium recycling projects launched by Shenhua has mastered the core technology of "One-Step Acid Leaching" to extract aluminum and gallium from fly ash, which has been recognized as advanced by global standard with first-of-the-kind technologies. Pilot facilities with $4000 \mathrm{t} / \mathrm{a}$ alumina and $360 \mathrm{~kg} / \mathrm{a}$ gallium capacity have come on line with three years of safe and stable operation so far, providing solid foundation for large-scale commercialization. Shenhua's "coal-power-fly ash-alumina" circular economy demonstration has been listed as one of the first "national mining resources comprehensive utilization demonstration projects," which is of great strategic significance to solving China's bauxite shortage.

\subsubsection{Systems factor synergy}

With system factors as subject, resources, environment and technology as constraints, efforts were made to achieve industrial balance and the integration of production, transportation and marketing through optimized coordination among systems. Industrial balance reflects the quantitative balance, and the industrial scale is adjusted 
and optimized by investment scale, structure and speed, which is the key to developing coal-based energy engineering strategies, industrial plans, and transformation of the industry. Integration of production, transportation and marketing reflects the improvement of quality, which requires across-the-board optimization and coordination of products, output and transportation capacity. This will gradually establish a market-oriented dynamic optimization model. Thanks to optimization and coordination of coal-based energy engineering factors, profit contribution from coal and power businesses have been optimized from $72.3 \%$ and $8.5 \%$ in 2008 to $36.7 \%$ and $39.7 \%$ in 2014 , leading to more balanced industrial structure and better coordination efficiency.

\section{4 "Two-wheel driven" innovation system}

"Two-wheel driven" is an important guarantee of the synergetic management system for coal-based energy engineering. The innovative idea of "management innovation as guidance, technological innovation as support, innovative talents as connection and engineering practice as subject" was proposed to continuously driving forward synergetic development of coal-based energy engineering.

Management innovation aims for the constant improvement of scientific management through analysis, forecast, decision-making and evaluation of the coal-based energy engineering and its systems. This includes systematic coordination among development environment study, market forecast, strategic decision-making, industry planning, institutional mechanisms matching, organizational control, talent cultivation and technological innovation. In its own practice, Shenhua came up with the management innovation concept with security as the core, establishing the risk-oriented internal control model. From the perspectives of risk prevention, operation improvement, value preservation and appreciation of state-owned assets and value creation, efforts have been made to strengthen evaluation on "intrinsic safety, quality and efficiency, innovation, resource-efficiency and environmental protection and harmonious development," promoting sound and sustainable development of the company.

Faced with problems such as low innovation capability and lack of relevant mechanisms, Shenhua initiated the innovation model to mobilize and operate internal and external innovative resources, aiming to make significant technological breakthroughs to provide reliable support for major projects through industry-university-research institute collaboration. In the case of Shenhua, externally the company took the lead in establishing the national "Strategic Alliance for Technological Innovation in Coal Development and Utilization," teaming up with research institutes, universities and companies and having invited 100-plus organizations to take part in more than 200 Shenhua innovation projects. Internally Shenhua established a "three-in-one" platform integrating fundamental research, $R \& D$ and commercialization of research findings. As a result, a technological innovation system, guided by technological demand, linked with industry-universityresearch institute collaboration and supported by the strategic alliance, is now taking shape which has dramatically boosted Shenhua's innovation and integration capabilities. A number of internationally or domestically leading technologies and equipment have since been developed. These include high-end large hydraulic support, aluminum and gallium extraction from fly ash, ultra-lowemission coal-fired plants and supercritical circulating fluidized bed for power generation. Shenhua has been leading the global coal industry in terms of relevant economic and technical indicators. Direct benefit from technological innovation exceeded $14.5 \times 10^{9} \mathrm{CNY}$ in 2014.

\section{Multi-objective dynamic optimization mode of energy engineering}

\subsection{Modeling design}

While pursing profit maximization, companies also need to fulfill their social responsibilities such as the reduction of pollutant emission. These two objectives are, nevertheless, contradictory to each other to some extent. This paper therefore designs a model from the perspective of multiindustry synergetic development for energy and applies Pareto's optimal method to achieve multi-objective optimization. Figure 1 illustrates the structure of multiobjective dynamic optimization model for energy engineering (MODOM-EE).

\subsection{Objectives}

In modeling the analysis of multi-industry synergetic development of energy companies, two types of objectives are mainly considered:

(1) The first type of objectives is to realize profit maximization, including operating income, total profits and alike. This research takes the total profit $P$ as the objective to be optimized.

$$
\max P=\sum_{t} \sum_{j}\left(M_{j, t} P P_{j}-A E C_{j, t}\right)
$$

where $j$ stands for various business segments of energy companies, $t$ means from 2015 to $2020, M_{j, t}$ is the annual output of various energy products, $P P_{j}$, is the profit per unit energy product, $A E C_{j, t}$ is the additional cost of deployment of new environmental protection technologies.

(2) The second type of objectives is to minimize pollutant emission $E$, including $\mathrm{SO}_{2}\left(E_{1}\right)$ and $\mathrm{NO}_{x}\left(E_{2}\right)$. This paper takes the total emission of $\mathrm{SO}_{2}$ and $\mathrm{NO}_{x}$ as the 


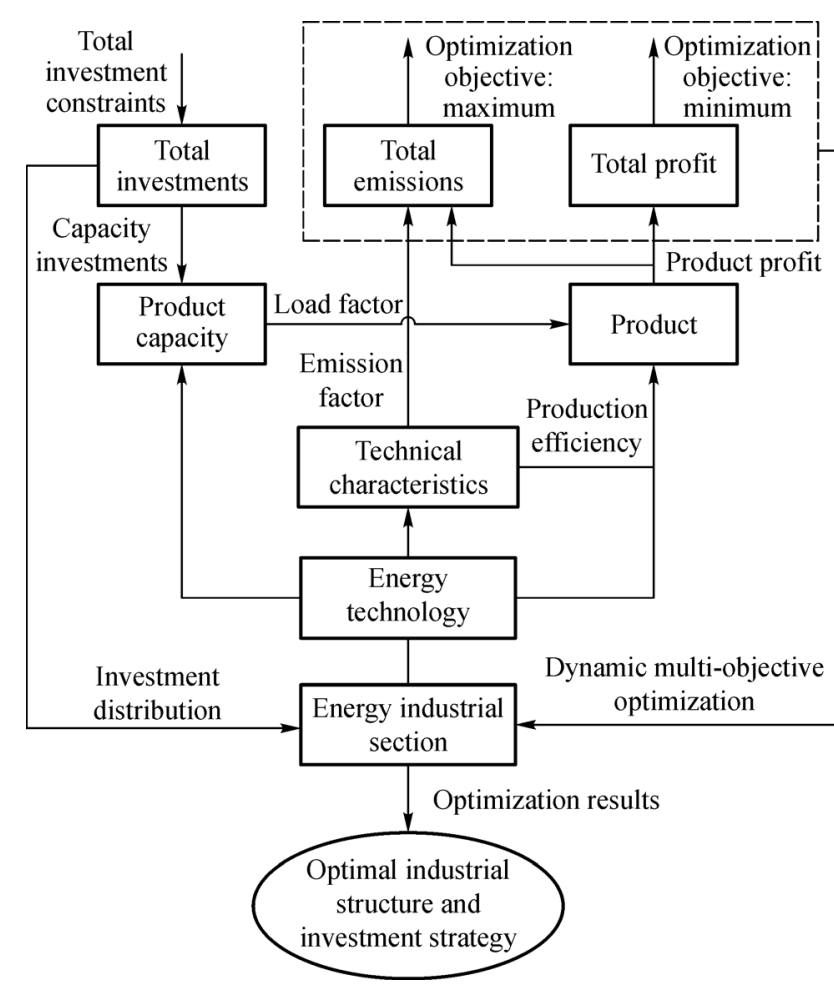

Figure 1. Multi-objective dynamic optimization model for energy engineering.

objectives to be optimized.

$$
\min E=\sum_{t} \sum_{j}\left[M_{j, t}\left(E_{1 j}+E_{2 j}\right)-D E_{j, t}\right]
$$

where $E_{1 j}, E_{2 j}$ are the emission of $\mathrm{SO}_{2}$ and $\mathrm{NO}_{x}$ per unit energy product respectively, $D E_{j, t}$ is the increased emission reduction per annum after the deployment of new environmental protection technologies.

\subsection{Major constraint functions}

Major constraint functions of business segments of energy companies are shown as follows:

(1) Annual production capacity function:

$$
\begin{aligned}
M C_{j, t} & =M C_{j, t-1}+M C A_{j, t}(t \neq 2015), M C_{j, 2015} \\
& =M C R_{j}+M C A_{j, 2015}
\end{aligned}
$$

where $M C_{j, t}$ is the annual production capacity of each energy product, $M C R_{j}$ is the base-year capacity of each energy product (using 2014 as the base year), $M C A_{j, t}$ is the annual additional capacity.

(2) Constraint function of annual additional capacity:

$$
M C A_{, 2015} \leqslant M C A_{j} \alpha_{j}, M C A_{j, t} \leqslant M C_{j, t-1} \alpha_{j}(t \neq 2015)
$$

where $\alpha_{j}$ is the maximal annual growth rate of production capacity

(3) Annual production function

$$
M_{j, t}=M C_{j, t} \beta_{j}
$$

where $\beta_{j}$ is the conversion factor of annual production and annual capacity

(4) Constraint functions of total additional construction investment:

$$
\begin{gathered}
T I_{t}=\sum_{j}\left(E I_{j, t}+I_{j, t}\right) \\
I_{j, t}=M C A_{j, t} \gamma_{j}
\end{gathered}
$$

where $T I_{t}$ is the total of annual additional investment in construction, $I_{j, t}$ is the annual additional construction investment of various business segments. $E I_{j, t}$ is the additional investment in environmental protection, $\gamma_{j}$ is the investment per unit capacity.

(5) Constraint function of additional construction investment :

$$
T I_{t} \varphi_{j} \leqslant I_{j, t} \leqslant T I_{t} \delta_{j}
$$

where $\varphi_{j}$ is the minimal investment ratio of $j$, and $\delta_{j}$ is the maximal investment ratio of $j$, which are determined by investment ratios in previous years and the prediction of future development.

(6) The function of investment in environmental protection

$$
D E_{j, t}=\frac{E I_{j, t}}{C E_{j}} \beta_{j}\left[\left(E_{1 j}+E_{2 j}\right)-\left(E N_{1 j}+E N_{2 j}\right)\right]
$$

$$
A E C_{j, t}=\frac{E I_{j, t}}{C E_{j}} \beta_{j} \varepsilon_{j}
$$

where $C E_{j}$ is the additional investment per unit capacity; $E N_{1 j}$ and $E N_{2 j}$ represent the emission per unit product before and after additional investment in environmental protection respectively; and $\varepsilon_{j}$ is the added cost per unit product due to additional investment in environmental protection.

\section{Empirical research on Shenhua engineering model optimization}

Shenhua engineering industrial chain is demonstrated in Figure 2, mainly covering coal, electricity (coal power and 
renewable energy generation), coal-to-liquids (direct coal liquefaction, indirect coal liquefaction, coal to olefin and coking) and transportation (railways, ports and shipping). Based on the development of each segment in 2014, this paper applied a multi-objective optimization to maximize total profit $P$ and minimize total emission $E$ between 2015 and 2020 .

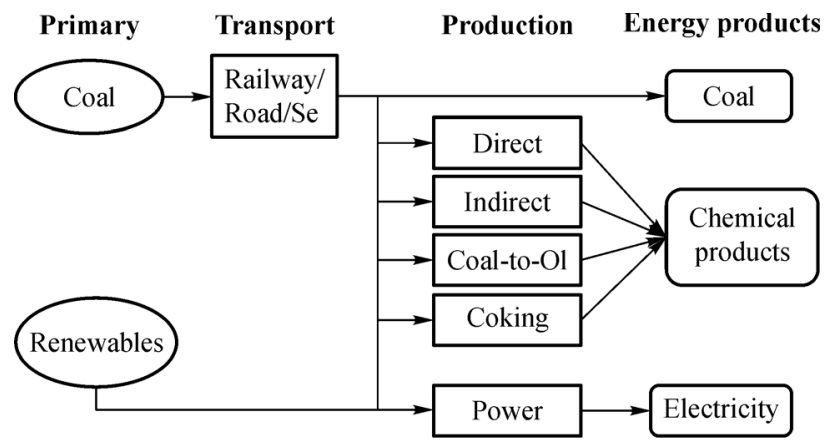

Figure 2. Diagram of Shenhua engineering factors and their relations.

4.1 The result and analysis of synergetic optimization of system factors

We apply multi-objective dynamic optimization model to optimize $P$ and $E$ of Shenhua industrial chain between 2015 and 2020 to come up with a feasible solution, as illustrated in Figure 3. In this figure, the dashed line represents a set of Pareto optimal solutions; the red rhombus represents the optimal solution for maximum profit with no consideration of emission reduction; and the green square represents the optimal solution for emission reduction with no consideration of profit.

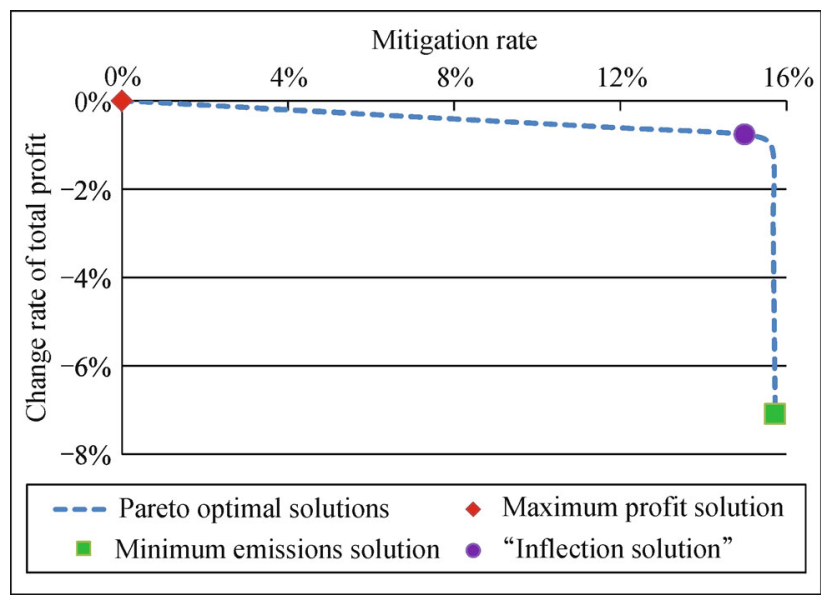

Figure 3. Optimal Pareto solution of Shenhua engineering system factors synergy.
From Figure 3, it can be seen that total profit and emission are a pair of nonlinear contradictory solutions. To obtain environmental benefits (the reduction of pollutant emission), it is imperative to "sacrifice" benefits of the company (profit). When emission reduction rate reaches $15 \%$, profits will decrease by $1 \%$; and when emission reduction rate continues to increase, profits will also see a rapid decrease, then comes the "inflection point," at which profit and environment collaborate the best in the current synergetic development of Shenhua industrial chain, as represented by the purple dot in Figure 3.

The target of dynamic optimization is to explore and identify the "inflection point" that enables maximal mitigation rate with minimal profit drop. Under the current industrial and technical conditions, to further reduce emission, it's necessary to think innovatively to promote resource-environment synergy.

4.2 The result and analysis of resource-environment synergy optimization

On the basis of synergetic optimization of system factors, through "two-wheel driven" system, Shenhua can reach the new balance between profit and environment by adjusting mentality in managing emissions in power segment and by developing green technology such as ultra-low-emission and renewable energy. The result of dynamic optimization is illustrated in Figure 4.

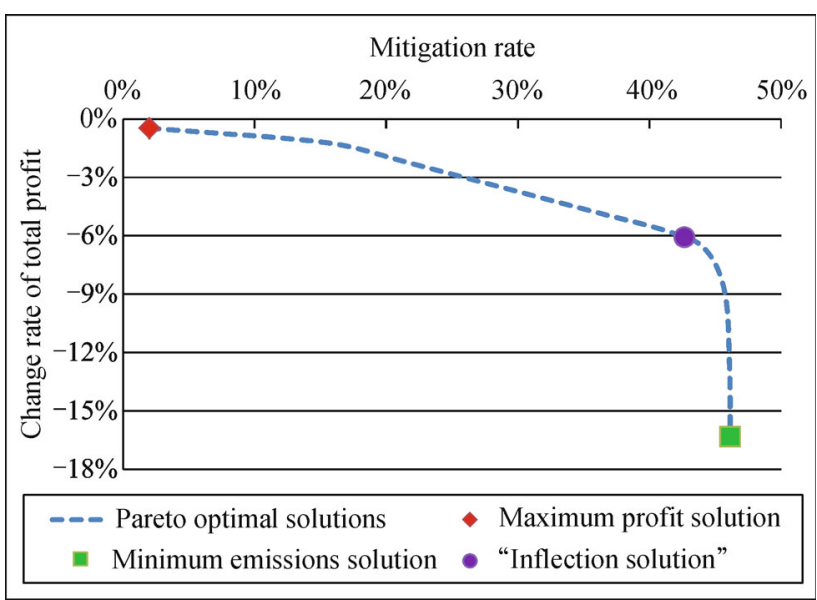

Figure 4. Optimal Pareto solution of Shenhua resource-environment synergy.

From Figure 4 it can be seen that while resourceenvironment synergy brings bigger potential of emissions mitigation, profit however also decreases dramatically. At the "inflection point," the emission reduction rate is $42 \%$ and the profit decreases by around 6\%, which is represented by the purple dot. When emission reduction rate continues to increase, the profit plummets accordingly and the maximal emission reduction rate reaches $46 \%$. 
4.3 The result and analysis of boundary extension synergetic optimization

Expanding into new industries can lead to extension of the system value chain. Based on Shenhua's own engineering practice, extraction of aluminum from fly ash produced by coal-fired generation is chosen as the target for optimization. The result of multi-objective dynamic optimization is illustrated in Figure 5.

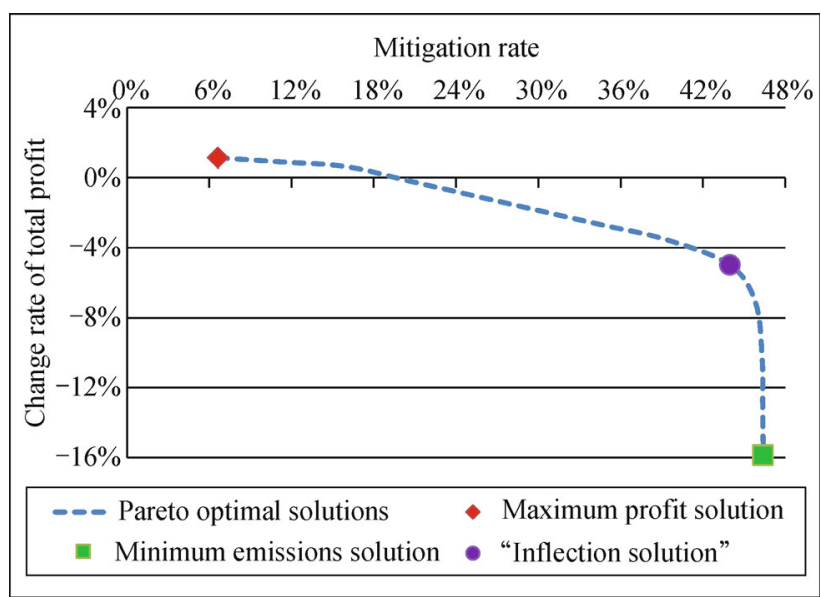

Figure 5. Optimal Pareto solution of Shenhua boundary extension synergy.

From Figure 5 it can be known that through synergetic development of boundary extension, the inflection point of profit and environment moves up and right noticeably. When the company has more potential for emission reduction, decreasing rate of profit declines accordinglywhen mitigation rate is $44 \%$, profit drops by around $5 \%$, as the purple point shown in Figure 5. By developing industries such as aluminum extraction from fly ash, Shenhua's total profit and emission reduction could both be improved with synergetic effect.

\subsection{The result and analysis of pollutant emission optimization}

Coal-fired power generation is the main source of pollutant emission in Shenhua. Figure 6 illustrates optimal Pareto solutions of total extra environmental investment as well as total coal-fired generation in 2020 .

From Figure 6, it can be seen that mitigation target could be met through adjusting the total amount of generation and investment in environmental protection. In the early stage, emission reduction can be achieved by reducing coal-fired power output; and when the total pollutant amount decreases to $16 \%$, ultra-low-emission with increased environmental investment could reduce total emission by $40 \%$.

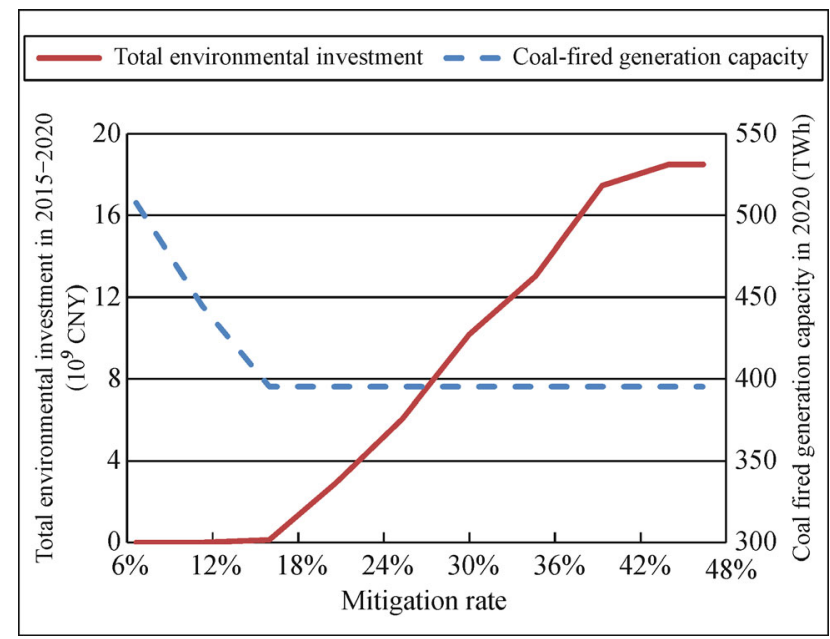

Figure 6. Optimal Pareto solution of total environmental investment and total power generation of the coal-fired power business.

Exploring the optimal "inflection point" of profit and environmental protection through systems factor synergy, resource-environment synergy and boundary extension synergy can not only guarantee profitability, but also fulfill emission mitigation obligations of the company. Shenhua's engineering study shows that synergy of environment and economy is at its best when the cumulative environmental investment reaches $15 \times 10^{9} \mathrm{CNY}$ between 2015 and 2020, thus contributing to sound and sustainable development of the company.

\section{Conclusions}

This paper conducted systematic analysis of problems causing unbalanced development in coal-based energy engineering, which mainly include unbalanced industrial structure due to inefficient resource allocation, low level of green development, discrepancies between development quality and benefits, and the under-development of technological innovation capability. Guided by the philosophy of engineering and dialectical materialism, based on quality, quantity and degree, this paper came up with the engineering management concept highlighting "factors coordination, systems synergy, dynamic optimization and three-dimension planning." In addition, the synergetic management system and the "two-wheel driven" support system are also proposed, with the establishment of a multiobjective dynamic optimization model for energy engineering (MODOM-EE). Based on Shenhua own engineering practice, it analyzes the Pareto optimal solution in three scenarios: best resource allocation, minimal impact on environment and maximal value creation.

Systems engineering management theory proposed in this paper summarized the author's research in systems 
engineering theory and practical experience over the years, which has helped to achieve remarkable results in Shenhua engineering practice and boosted the company's leapforward development and transformation. In the meantime, the research findings and engineering practice could also serve as guidance and reference for development of other multi-industry energy engineering projects.

\section{References}

Liu, H. (1992). The theory of contradictory fractal: the relation between the rule of contradiction and systems science. Science Technology and
Dialectics, 3, 1-8.

Shenhua Group Corporation Limited. (2014). The annual report of Shenhua Group Corporation Limited.Beijing: Shenhua Group Corporation Limited.

The National Bureau of Statistics of the People's Republic of China. (2013). China Statistics Year Book. Beijing: China Statistics Press.

The National Bureau of Statistics of the People's Republic of China.

(2014). The third national economic survey main data bulletin (NO.2). Retrieved from http://www.stats.gov.cn/tjsj/zxfb/201412/ t20141216_653695.html.

Xie, K. (2014). A Study on Clean, Efficient and Sustainable Exploration and Utilization of Coal in China. Beijing: Science Press.

Yin, R., \& Wang, Y. (2007). The Philosophy of Engineering. Beijing: Higher Education Press. 